\title{
3 Case Reports of Fulminant Hepatitis A after Karballa Pilgrimage
}

\author{
Maryam Ansari Chaharsoughi ${ }^{*}$, Hasan Salehi ${ }^{1}$, Alireza Emami ${ }^{1}$, \\ Mohammadreza Yazdani' ${ }^{1}$, Mohammad Mahdi Salehi ${ }^{2}$ \\ ${ }^{1}$ Department of Infectious Disease, Alzahra Hospital, Isfahan, Iran \\ ${ }^{2}$ School of Dentistry, Isfahan University of Medical Sciences, Isfahan, Iran \\ Email: ^m4ansari@yahoo.com, h-salehi@med.mui.ac.ir, a-emami35@yahoo.com,yazdani@med.mui.ac.ir, \\ Mahdi_salehi1024@yahoo.com
}

How to cite this paper: Chaharsoughi, M.A., Salehi, H., Emami, A., Yazdani, M. and Salehi, M.M. (2018) 3 Case Reports of Fulminant Hepatitis A after Karballa Pilgrimage. Advances in Infectious Diseases, 8, 33-38. https://doi.org/10.4236/aid.2018.82005

Received: March 21, 2018

Accepted: May 18, 2018

Published: May 21, 2018

Copyright (c) 2018 by authors and Scientific Research Publishing Inc. This work is licensed under the Creative Commons Attribution International License (CC BY 4.0).

http://creativecommons.org/licenses/by/4.0/

\begin{abstract}
Introduction: Fulminant hepatitis is a very rare disease that occurs as an acute liver failure within eight weeks of the onset of symptoms following hepatitis A in adults or in patients with a history of chronic hepatitis B or C [1]. Case presentation: There were three cases in this research. The first case was a self-employed male patient aged 26 years from Gaz Borkhar, admitted to Al-Zahral Hospital on January 1, 2016 for fever, chills and vomiting. The second patient was a 20 -year-old male athlete from Lenjan and was hospitalized on May 3, 2016 for fever, chills, anorexia, yellowing of the skin, and low consciousness. The third case was a 20 -year-old male employee from Isfahan who visited Al-Zahra Hospital for developing nausea, vomiting, and discolored urine, followed by icterus. Conclusion: all patients were young without any underlying disease. Although the disease had a very progressive course leading to coma, all cases fortunately survived through supportive measures and returned to their normal lives.
\end{abstract}

\section{Keywords}

Fulminant Hepatitis, Deep Coma, Positive Hepatitis A Serology, Liver Enzyme Elevation

\section{Introduction}

Fulminant hepatitis is a partially known, yet complex, clinical disease that continues to remain a serious clinical challenge [2]. It is an infectious disease often caused by hepatitis B virus [3]. Hepatitis $\mathrm{A}$ is known as a mild liver disease, which rarely causes fulminant hepatitis [4] [5]. 
Therefore, fulminant hepatitis is rarely seen in hepatitis A, and most often occurs in those with an underlying disease. Patients with chronic liver diseases are prone to fulminant hepatitis failure, and thus immunization is necessary [6]. The mortality rate from this disease is slightly higher than $80 \%$ in case of getting into deep coma [1]. It is worth noting that fulminant hepatitis $\mathrm{A}$ is a rare problem in young individuals without any underlying disease. Hepatitis A is a self-limited disease in children, but symptomatic in adults. Reports indicate high rate of fulminant hepatitis in patients with an underlying chronic liver disease without cirrhosis in Italy [7] [8] [9] whereas it is unusual among children and rare in adults [10] [11] [12] [13] and [14].

In patients introduced to us, young individuals with acute hepatitis A have got into a state of deep coma and completely recovered. Our patients have not positive family history of hepatitis or liver failure. Our patients did not mention any history of acute hepatitis B or C.

\section{Case Presentation}

\section{First case:}

The first case was a self-employed male patient aged 26 years from Gaz Borkhar, admitted to Al-Zahral Hospital on January 1, 2016. The patient had suffered from fever, chills, occasional coughing and vomiting 3-4 weeks before the admission. He had travelled to Karbala two weeks before the admission. The case developed jaundice, and gradually lost consciousness and got into a state of deep coma during the hospitalization. He did not mention any underlying disease. Except for the yellowing of the eyes, no organomegaly, adenopathy, or organ and limb abnormality was observed. The liver enzymes were very high at the admission $(\mathrm{AST}=6400, \mathrm{ALT}=8000, \mathrm{INR}=21.7, \mathrm{Bil}=10$, and Bil $\mathrm{D}=6.6, \mathrm{alb}=1.8)$ and HAVIgM was positive (Table 1). Ultrasound results of the liver and spleen were normal. During the hospitalization period, INR reached nine but did not cause bleeding. The patient received maintenance and supportive treatments with lactulose syrup, paramomycin (250 g) capsules, and NAC tablets, and gradually regained his urge to defecate. Enzyme levels became normal .INR, AST, ALB, and ALT levels were gradually modified to 5.1, 208, 2.2, and 123, respectively, and the patient gradually regained consciousness after one week. The case was discharged after 15 days with good general health and full consciousness.

\section{Second case:}

The second patient was a 20-year-old male athlete and student from Lenjan.

Table 1. Laboratory findings in case 1.

\begin{tabular}{cccccc}
\hline Laboratory & AST & ALT & INR & Total Bil & Alb \\
\hline At admission & 6400 & 8000 & 21.7 & 10 & 1.8 \\
After 1 week & 208 & 123 & 5.1 & 5 & 2.2 \\
\hline
\end{tabular}

ALT, alanin amino transferase; AST, aspartate amino transferase; Total Bil, total Bilirubin; Alb, Albumin; INR, international normalized Ratio (Normal range: 2 - 3). 
He was hospitalized on May 3, 2016 for fever, chills, anorexia, yellowing of the skin, and low consciousness. The patient had travelled to Khuzestan 20 days before hospitalization and gradually developed fever and chills after his return. Finally, he developed jaundice and low consciousness. The patients got into a state of deep coma and thus he was intubated at admission.

The patient did not mention any history of having a specific disease but he had a contact to Karbala travelers.

At admission, he experienced loss of consciousness and had icterus, but no organomegaly was observed; in addition, his BP and T levels were 120/90 and 39 respectively.

We observed in lab data HAV IgM $=3.3$, AST $=2500, \mathrm{ALT}=2960, \mathrm{BIL}$ TOTAL $=9.09, \mathrm{ALB}=2$ and $\mathrm{INR}=43.2$ at admission and changed to AST $=$ $2800, \mathrm{ALT}=3340$, and INR $=36.2$ the next day (Table 2). The initial ultrasound test showed an abnormal liver size $(165 \mathrm{~cm})$. After one week, the liver size was $159 \mathrm{~cm}$ and parenchymal echogenicity slightly increased.

Four days after the admission, during which the patient received treatment with hydration, lactulose, and high-carbohydrate diet, these values changed to $\mathrm{AST}=265, \mathrm{ALT}=712, \mathrm{BIL} \mathrm{TATAL}=6, \mathrm{ALB}=2.4$ and $\mathrm{INR}=56.1$. The patient was extubated four days after the hospitalization and discharged with a good general health status.

\section{Third case:}

The case was a 20 -year-old male employee from Isfahan who visited Al-Zahra Hospital for developing nausea, vomiting, and discolored urine, followed by icterus. The patient had travelled to Karbala 13 days before the admission. He experienced loss of consciousness during the hospitalization period. The patient did not mention any history of having an underlying disease. At admission, his $\mathrm{T}$ and BP levels were 38 and 100/70, respectively, and examination did not show any positive result, except for icterus. The patient was intubated for 4 days during the hospitalization period. He regained consciousness and was extubated after four days.

At admission, the AST, ALT, and BIL TOTAL, ALB and INR values were 218, 171 , and $8.11,2.3$ and 4 respectively. During the hospitalization period $\left(7^{\text {th }}\right.$ days of admission), the INR, ALT, and AST, BIL TOTAL and ALB values were 1.9, 1150 , and 425,7 and 2 respectively at $15^{\text {th }}$ days of admission the values were 1.5 , $150,100,4$, and 2.6 respectively (Table 3 ). Although, the ultrasound examination of the patient showed a mild increase in hepatic echogenicity, the liver size

Table 2. Laboratory findings in case 2.

\begin{tabular}{rccccc}
\hline Laboratory & AST & ALT & INR & Total Bil & Alb \\
\hline At admission & 2500 & 2960 & 9.09 & 43.2 & 2 \\
Forth Day & 265 & 712 & 6 & 56.1 & 2.4 \\
\hline
\end{tabular}

ALT, alanin amino transferase; AST, aspartate amino transferase; Total Bil, total Bilirubin; Alb, Albumin; INR, international normalized Ratio (Normal range: 2 - 3). 
Table 3. Laboratory findings in case 3.

\begin{tabular}{cccccc}
\hline Laboratory & AST & ALT & INR & Total Bil & Alb \\
\hline At admission & 218 & 171 & 4 & 8.11 & 2.3 \\
7th day & 425 & 1150 & 1.9 & 7 & 2 \\
15th day & 100 & 150 & 1.5 & 4 & 2.6 \\
\hline
\end{tabular}

ALT, alanin amino transferase; AST, aspartate amino transferase Total Bil, total Bilirubin; Alb, Albumin; INR, international normalized Ratio (Normal range: 2 - 3).

was normal. Ultrasound results of the patient were normal during the hospitalization period. After the administration of the maintenance treatment with lactulose and a high-carbohydrate diet, the symptoms were eliminated and test results became normal.

\section{Discussion and Conclusions}

In this study, two patients had travelled to Karbala (Iraq) and one patient had travelled to Khuzestan (Iran) before the admission but he had contacted with Karbala traveler. All three cases were admitted with hepatitis symptoms, and experienced loss of consciousness and got into a state of deep coma before the admission or during the hospitalization period. All three cases were suffering from jaundice. In all three cases, elevated liver enzymes and clotting disorders (INR) were observed. According to the test results, the HAVIgM level was high, and thus they became susceptible to fulminant hepatitis A. Moreover, all cases had positive hepatitis serology, and negative hepatitis B and C tests. Interestingly, all patients were young without any underlying disease. Although the disease had a very progressive course leading to coma, all cases admitted to ICU.

Their diets were high carbohydrate and also lactulose syrup was prescribed. The authors report a cluster of 5 serologically-confirmed cases of acute Hepatitis A Virus (HAV), all serum IgM positive for HAV Genotype 1A. This is on a background of only 2 other cases notified to HSE-South in 2016 to date, both travel related. There was a considerable delay in notification in two out of 5 cases. This case report highlights the importance of prompt notification of Hepatitis A, as timely notification would have facilitated prompt contact vaccination and might well have prevented illness in two subsequent household contacts [15].

Fulminant case is rare but needs to be managed appropriately and may require transplantation in extremely ill patients [15].

Poor hygienic and sanitary condition allow HAV to spread therefore availability of effective vaccine against hepatitis has markedly affected the epidemiology of hepatitis [16].

Paradoxically average age of reported cases is higher than in highly endemic area, perhaps high level virus circulates in a population.

The most serious complication of hepatitis A is fulminant hepatic failure.

Danger signs include excitability, confusion, insomnia, sever vomiting, liver test abnormal and prolonged PT. 
Laboratory diagnose is helpful .We detected HAVIgM in three cases.

We warn the Karbala traveler about the foodborne and waterborne transmission.

Travelers who acquire hepatitis during trip may transmit to others [16].

HAV can remain infectious for long periods of time [16].

Susceptible persons who travel to endemic area should be vaccinated to prevent infection.

\section{References}

[1] Bennett, J., Dolin, R. and Blaser, M.J. (2012) Principles and Practice of Infectious Diseases. Second Volume, 2, 1441.

[2] Kjaergard, L.L., Liu, J., Als-Nielsen, B. and Gluud, C. (2003) Artificial and Bioartificial Support Systems for Acute and Acute-on-Chronic Liver Failure: A Systematic Review. JAMA, 289, 217-222. https://doi.org/10.1001/jama.289.2.217

[3] Belongia, E.A., Costa, J., Gareen, I.F., Grem, J.L., Inadomi, J.M., Kern, E.R., McHugh, J.A., Petersen, G.M., Rein, M.F., Sorrell, M.F., Strader, D.B. and Trotter, H.T. (2008) NIH Consensus Development Statement on Management of Hepatitis B. NIH Consens State Sci Statements, 25, 1-29.

[4] Oh, S.H., Lee, J.H., Hwang, J.W., Kim, H.Y., Lee, C.H., Gwak, G.Y., et al. (2009) Four Patients with Hepatitis A Presenting with Fulminant Hepatitis and Acute Renal Failure and Who Underwent Liver Transplantation. Korean Journal of Hepatology, 15, 362-369. https://doi.org/10.3350/kjhep.2009.15.3.362

[5] Heo, N.Y., Lim, Y.S., Kang, J.M., Oh, S.I., Park, C.S., Jung, S.W., et al. (2006) Clinical Features of Fulminant Hepatic Failure in a Tertiary Hospital with a Liver Transplant Center in Korea. Korean Journal of Hepatology, 12, 82-92.

[6] American Academy of Pediatrics (2015) Red Book 30 $30^{\text {th }}$ Edition. 391.

[7] Battegay, M., Naef, M. and Bucher, H.C. (1998) Hepatitis Associated with Hepatitis A Superinfection in Patients with Chronic Hepatitis C. New England Journal of Medicine, 338, 1771-1772. https://doi.org/10.1056/NEJM199806113382413

[8] Stroffolini, T., Almasio, P.L., Di Stefano, R., et al. (2002) Anti-Hepatitis A Virus Seroprevalence and Seroconversion in a Cohort of Patients with Chronic Viral Hepatitis. Digestive and Liver Disease, 34, 656-659.

https://doi.org/10.1016/S1590-8658(02)80209-2

[9] Tassopoulos, N., Papaevangelou, G., Roumeliotou-karayannis, A., et al. (1985) Double Infections with Hepatitis A and B Viruses. Liver, 5, 348-353. https://doi.org/10.1111/j.1600-0676.1985.tb00258.x

[10] Forbes, A. and Williams, R. (1990) Changing Epidemiology and Clinical Aspects of Hepatitis A. British Medical Bulletin, 46, 303-318. https://doi.org/10.1093/oxfordjournals.bmb.a072400

[11] Yao, G. (1991) Clinical Spectrum and Natural History of Viral Hepatitis A in a 1988 Shanghai Epidemic. In: Hollinger, F.B., Lemon, S.M. and Margolis, H., Eds., Viral Hepatitis and Liver Disease, Williams and Wilkins, Baltimore, 14-20.

[12] Keeffe, E.B. (1995) Is Hepatitis A More Severe in Patients with Chronic Liver Disease? Am J Gastroenterol, 90, 201-205.

[13] Willner, I.R., Uhi, M.D., Howard, S.C., Williams, E.Q., Riely, C.A. and Waters, B. (1998) Serious Hepatitis A: An Analysis of Patients Hospitalized during an Urban Epidemic in the United States. Annals of Internal Medicine, 128, 111-114. 
https://doi.org/10.7326/0003-4819-128-2-199801150-00006

[14] Vento, S., Garofano, T., Renzini, C., et al. (1998) Fulminant Hepatitis Associated with Hepatitis A Virus Superinfection in Patients with Chronic Hepatitis C. New England Journal of Medicine, 338, 286-290.

https://doi.org/10.1056/NEJM199801293380503

[15] Ferris, H.A., Dillon, A. and O’Sullivan, M.B. (2017) A Cluster of Hepatitis A Viral Infection in HSE South. Irish Medical Journal, 110, 587.

[16] Francisco, A., et al. (2015) Hepatitis A Virus. Mandell, Douglas and Bennett's Principles and Practice of Infectious Disease. 2015 Third Volume, 3, 2095-2109. 